\title{
Some observations on the penetration of antibiotics through mucus in vitro
}

\author{
B. A. SAGGERS AND DAVID LAWSON \\ From Queen Mary's Hospital for Children, Carshalton, Surrey
}

SYNOPSIS A study has been made on the penetration values in vitro of antibiotics through hog gastric mucin at $p \mathrm{H} 7 \cdot 4$. Determinations have also been done on the binding of antibiotics to mucus and human plasma. The mucolytic agent $\mathrm{N}$-acetyl cysteine has been studied in regard to its effect on antibiotics penetrating mucus and for any possible inactivation of antibiotics.

The chemotherapeutic treatment for cystic fibrosis patients has for some years utilized a wide range of antibiotics in the control and prevention of bacterial chest infections. A knowledge of the rate at which antibiotics diffuse into mucus and the concentrations of antibiotics obtained therein would be helpful in the management of cystic fibrosis. There are practical difficulties in assessing the clinical effect of one of a number of variables, which may include the use of one or more antibiotics, physiotherapy, and mucolytic agents, against the variable natural history of each inflammatory episode. The investigations reported here were designed to determine the effectiveness of antibiotics in penetrating mucus in vitro, by simulating conditions which would be expected when giving the antibiotics by aerosol or via the blood stream in the hope of giving a more accurate assessment of relative antibiotic penetration values. Experiments were also done to determine the effect of the mucolytic agent $\mathrm{N}$-acetyl cysteine (Airbron) on antibiotic penetration values.

\section{MATERIALS AND METHODS}

TEST ANTIBIOTICS A wide range of antibiotics commonly used to combat both Gram-positive and Gram-negative bacteria was studied. These were ampicillin, cephalosporin (Ceporin), cloxacillin, erythromycin gluceptate, fucidin, lincomycin, methicillin, neomycin, novobiocin, penicillin $G$, polymyxin $B$, quinacillin, streptomycin, sulphadiazine, sulphamezathine, and tetracycline hydrochloride.

TEST MUCIN Hog gastric mucin (L. Light \& Co.) was used for all the general tests. The mucin powder was made up in $0.1 \mathrm{M} \mathrm{pH} \mathrm{7.4} \mathrm{phosphate} \mathrm{buffer} \mathrm{(Sorensen)} \mathrm{at}$ concentrations from 1 to $20 \%(w / v)$, well mixed and incubated for one hour at $37^{\circ} \mathrm{C}$. before use.

Received for publication 4 April 1966.
MUCOLYTIC AGENT N-acetyl cysteine (Airbron, B.D.H. Ltd.) at $5 \%(\mathrm{w} / \mathrm{v})$ was the only mucolytic agent used in this series of experiments.

DETERMINATIONS ON THE ANTIBIOTIC-TO-MUCUS BINDING These experiments were done before those to measure the penetration of antibiotics into mucus, in order that any antibiotic binding could be considered in the evaluation of the penetration values. The technique used was basically that of Bond, Lightbown, Barber, and Waterworth (1963) which separates free antibiotic from proteinbound antibiotic by means of ultrafiltration through a Visking membrane under negative pressure. A $20 \mathrm{ml}$. solution of the test antibiotic was made up at $10 \mu \mathrm{g} . / \mathrm{ml}$. in $0.1 \mathrm{M} p \mathrm{H} 7.4$ phosphate buffer and divided into two equal portions $\mathbf{A}$ and $\mathbf{B}$. Hog gastric mucin was added to volume $A$ to give a concentration of $1 \%(w / v)$. The antibiotic/mucus mixture and the antibiotic solution volume $\mathrm{B}$ were incubated at $37^{\circ} \mathrm{C}$. for one hour before use. Volume A was then ultrafiltered for six hours at a negative pressure of $120 \mathrm{~mm}$. The ultrafiltrate produced was divided into two portions: one portion was checked for the presence of protein by a biuret test, and if negative the second portion was assayed for antibiotic content by a cup plate assay against standards made up from the antibiotic solution volume $B$. If the ultrafiltrate contained any protein it was discarded and the experiment was repeated. The organisms used in the microbiological assays of the antibiotics were those recommended by the National Collection of Type Cultures (N.C.T.C.). The test sulphonamides could not be assayed in this way due to assay difficulties, so the sulphonamide ultrafiltration tests were run at $1,000 \mu \mathrm{g}$. $/ \mathrm{ml}$. and the ultrafiltrate was assayed by the chemical method of Bratton and Marshall (1939). The percentage binding of the antibiotics to hog mucin was determined from the differences between the antibiotic content of the ultrafiltrate and the original $10 \mu \mathrm{g} . / \mathrm{ml}$. solution. When the hog mucin showed evidence of antibiotic binding, ultrafiltration experiments were also done using fibrocystic mucus at $1 \%(w / v)$.

PROTEIN BINDING TO HUMAN PLASMA The protein binding of the antibiotics to pooled human plasma from 
20 normal adults was determined by the ultrafiltration technique. The test antibiotics were made up at $10 \mu \mathrm{g} . / \mathrm{ml}$. in $p \mathrm{H} \mathrm{7.4} \mathrm{phosphate} \mathrm{buffer} \mathrm{for} \mathrm{standard} \mathrm{controls,} \mathrm{and} \mathrm{in}$ the pooled human plasma for ultrafiltration. The suggestion of Bond (1964) that at least $95 \%$ serum should always be present in protein-binding determinations was observed in all experiments. The pooled human plasma tested was then used as a vehicle for supplying antibiotics in the plasma to mucus diffusion experiments.

N-ACETYL CYSTEINE INACTIVATION OF ANTIBIOTICS Nacetyl cysteine has been found to inactivate some antibiotics (Lawson and Saggers, 1965), and as experiments using $\mathrm{N}$-acetyl-cysteine-treated mucus would be done in this survey, further tests were carried out to determine if any of the test antibiotics were inactivated. The antibiotics were tested by titrating them against standard assay organisms (N.C.T.C.) with and without $5 \%(\mathrm{w} / \mathrm{v})$ $\mathrm{N}$-acetyl cysteine in the medium. Differences in the minimal inhibitory concentrations of the antibiotics to the test organisms due to the presence of $\mathrm{N}$-acetyl cysteine were noted. The above technique was not suitable for testing inactivation of sulphonamides as the $5 \%$ $\mathrm{N}$-acetyl cysteine reacted with the laked blood added to the medium as a desensitizing agent. The effect of $\mathrm{N}$-acetyl cysteine on the sulphonamide drugs was therefore determined using the chemical assay method of Bratton and Marshall (1939). Sulphonamide solutions were used at $1,000 \mu \mathrm{g} . / \mathrm{ml}$. in $p \mathrm{H} 7.4$ phosphate buffer with and without $5 \% \mathrm{~N}$-acetyl cysteine and then tested for free and conjugated sulphonamide drug.

MEASUREMENT OF ANTIBIOTIC DIFFUSION THROUGH MUCIN A microdiffusion apparatus designed specifically for the purpose of measuring the diffusion of antibiotics through $1 \mathrm{~mm}$. columns of mucin (Saggers, 1966) was used in all diffusion experiments. The effect of hog mucin solutions at $1,5,10,15$, and $20 \%(w / v)$ on antibiotic penetration was determined by measuring the amount of antibiotic that diffused through a $1 \mathrm{~mm}$. column of hog mucin in 24 hours at $37^{\circ} \mathrm{C}$. by microbiological assay. The effect of $\mathrm{N}$-acetyl cysteine at $5 \%(\mathrm{w} / \mathrm{v})$ on the diffusion rates of antibiotics through hog mucin was also studied. The hog mucin for these experiments was prepared by incubating the mucin in a $5 \%$ solution of $\mathrm{N}$-acetyl cysteine in $\mathrm{pH} \mathrm{7.4}$ phosphate buffer for one hour at $37^{\circ} \mathrm{C}$.

Antibiotic concentrations of $200 \mu \mathrm{g} . / \mathrm{ml}$. in $p \mathrm{H} 7.4$ phosphate buffer were used to study the effect of aerosol to mucus penetration and at $8 \mu \mathrm{g}$. $/ \mathrm{ml}$. in plasma to study blood to mucus penetration.

\section{RESULTS}

MUCUS TO ANTIBIOTIC BINDING Neomycin, novobiocin, polymyxin $B$, streptomycin, and the tetracyclines were the only antibiotics to show binding to $1 \%$ hog mucin (Table I). The tetracyclines all formed an orange-yellow pigmented complex with the hog mucin, which was insoluble in $p H \mathbf{H} 7.4$ phosphate buffer. Albert $(1952,1956)$ found that the tetracyclines formed orange-yellow chelation compounds

TABLE I

BINDING OF ANTIBIOTICS TO $1 \%(w / v)$ HOG MUCIN AT pH $7 \cdot 4$

\begin{tabular}{lll} 
Antibiotic & Assay Organism & $\begin{array}{l}\text { Percentage of } \\
\text { Mucus-bound } \\
\text { Antibiotic }\end{array}$ \\
\hline Ampicillin & Sarcina lutea & 0 \\
Cephalosporin & Sarcina lutea & 0 \\
Chlortetracycline & Bacillus pumilus & 100 \\
Cloxacillin & Sarcina lutea & 0 \\
Erythromycin & Sarcina lutea & 0 \\
Fucidin & Oxford staphylococcus & 0 \\
Lincomycin & Sarcina lutea & 0 \\
Methicillin & Sarcina lutea & 0 \\
Oxytetracycline & Klebsiella pneumoniae & $72 \cdot 5$ \\
Neomycin & Bacillus pumilus & $94 \cdot 0$ \\
Novobiocin & Bacillus subtilis & 30 \\
Paromomycin & Bacillus subtilis & 0 \\
Penicillin G & Sarcina lutea & 0 \\
Polymyxin B & Bordatella bronchiseptica & $25 \cdot 0$ \\
Streptomycin & Bacillus subtilis & $25 \cdot 0$ \\
Sulphadiazine & Colorimetric & Conjugated \\
Sulphamezathine & Colorimetric & Conjugated \\
Tetracycline HCl & Bacillus pumilus & $87 \cdot 5$
\end{tabular}

in the presence of certain metal ions. The possibility of chelation occurring with hog mucin was investi- $\vec{\circ}$ gated by pre-chelating the metal ions in the mucin $\mathscr{\odot}$ with $0.3 \mathrm{M}$ ethylene diamine tetracetic acid (E.D.T.A.) before the addition of the tetracyclines. The results of the mucus to tetracyclines binding experiments in the presence of E.D.T.A. (Table II) show a reduction in the binding of hog mucin.

TABLE II

EFFECT OF 0.3M E.D.T.A. ON BINDING OF TETRACYCLINES TO HOG MUCIN

Antibiotic

Percentage Binding to Hog Mucin

Without E.D.T.A. With 0.3 M E.D.T.A

Chlortetracycline

Oxytetracycline

100

Tetracycline $\mathbf{H C l}$

$72 \cdot 5$

$72 \cdot 5$
$87 \cdot 5$

66

45

Ultrafiltration experiments were repeated using 9 $1 \%(w / v)$ fibrocystic mucus with the antibiotics that showed binding to hog mucin. These experiments showed that antibiotic to mucus binding also $\mathbb{N}$ occurred with fibrocystic mucus (Table III), but in different proportions.

TABLE III

BINDING OF ANTIBIOTICS TO $1 \%(w / v)$ FIBROCYSTIC MUCUS AT pH $7 \cdot 4$

Antibiotic Assay Organism $\quad \begin{aligned} & \text { Percentage of } \\ & \text { Mucus-bound } \\ & \text { Antibiotic }\end{aligned}$

\begin{tabular}{lll}
\hline Neomycin & Bacillus pumilus & 50 \\
Novobiocin & Bacillus subtilis & 40 \\
Polymyxin B & Bordatella bronchiseptica & Not tried \\
Streptomycin & Bacillus subtilis & 100 \\
Tetracycline HCl & Bacillus pumilus & 5
\end{tabular}


PLASMA BINDING OF THE ANTIBIOTICS The results of the experiments to determine the protein binding of the test antibiotics to pooled human plasma were in the range of those expected for the test antibiotics.

EFFECT OF N-ACETYL CYSTEINE ON ANTIBIOTICS Lawson and Saggers (1965) found that ceporin, the penicillins, and tetracycline hydrochloride were inactivated by $5 \%(\mathrm{w} / \mathrm{v}) \mathrm{N}$-acetyl cysteine. The effect of $\mathrm{N}$-acetyl cysteine on these antibiotics was not reinvestigated in this series of experiments. Neomycin and paromomycin were the only test antibiotics inactivated by $5 \%(\mathrm{w} / \mathrm{v}) \mathrm{N}$-acetyl cysteine (Table IV).

\section{TABLE IV}

EFFECT OF N-ACETYL CYSTEINE ON ANTIBIOTICS

Test Antibiotic

Minimal Inhibitory Concentrations $(\mu g . / m l$.

Without $\mathrm{N}$-acetyl With $\mathrm{N}$-acetyl

Cysteine Cysteine

\begin{tabular}{lll}
\hline Lincomycin & $0 \cdot 1$ & $0 \cdot 1$ \\
Neomycin & $1-2$ & $2-5$ \\
Novobiocin & $1-2$ & $1-2$ \\
Paromomycin & $1-2$ & 10 \\
Polymyxin $\mathbf{B}^{1}$ & 40 & 10 \\
Streptomycin & $0 \cdot 1-0 \cdot 5$ & $0 \cdot 1-0 \cdot 5$ \\
Sulphadiazine & - & $100 \%$ conjugated \\
Sulphamezathine $^{2}$ & - & $100 \%$ conjugated
\end{tabular}

${ }^{1}$ Assayed using Pseudomonas pyocyanea

${ }^{2}$ Assayed by chemical assay

Polymyxin B, using Pseudomonas pyocyanea as the assay organism, showed a reduction in the minimal inhibitory concentration of $30 \mu \mathrm{g} . / \mathrm{ml}$. in the presence of $5 \%(\mathrm{w} / \mathrm{v}) \mathrm{N}$-acetyl cysteine. True synergism between polymyxin $\mathrm{B}$ and $\mathrm{N}$-acetyl cysteine could not be demonstrated using conventional microbiological techniques, so investigations were done to determine if it altered the physical characteristics of the bacterial growth medium. The $p \mathrm{H}$ of the medium was unaffected by the addition of $5 \%(\mathrm{w} / \mathrm{v}) \mathrm{N}$-acetyl cysteine, but the $\mathrm{E}$ h potential was reduced to $+0.227 \mathrm{mv}$., which was more reduced than a 24-hour broth culture of Ps. pyocyanea. The test medium plus $10 \%(\mathrm{w} / \mathrm{v}) \mathrm{N}$-acetyl cysteine was found to inhibit the growth of Ps. pyocyanea without polymyxin $\mathrm{B}$ being present, so the apparent synergism of the polymyxin $\mathrm{B}$ and $\mathrm{N}$-acetyl cysteine was due to a combination of the inhibitory effects of the antibiotic and mucolytic agent.

The chemical assays for the inactivation of the sulphonamides with $\mathrm{N}$-acetyl cysteine showed that complete conjugation of the sulphonamide drugs occurred after one hour at $37^{\circ} \mathrm{C}$.

AEROSOL PENETRATION OF ANTIBIOTICS THROUGH HOG MUCIN The concentrations of the antibiotics that

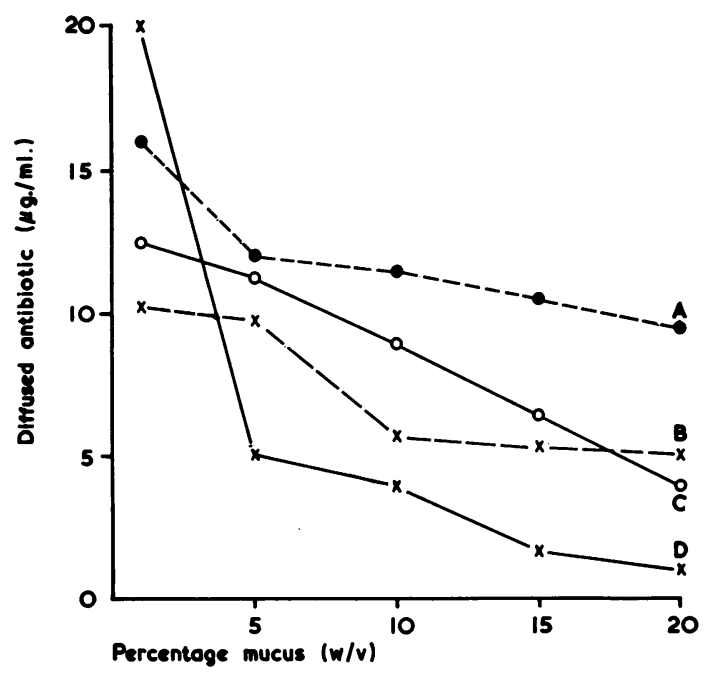

FIG. 1. The concentrations of antibiotics obtained after diffusion through $1 \mathrm{~mm}$. columns of 0 to $20 \%$ hog mucin.

A Lincomycin

B Tetracycline $\mathrm{HCl}$

C Fucidin

D Penicillin $G$

diffused through $1 \mathrm{~mm}$. columns of hog mucin did not decrease linearly with an increase in column mucus concentration. The concentration of antibiotic obtained after diffusion through $1 \%$ hog mucin was in most cases much higher than that obtained after diffusion through $5 \%$ hog mucin (Fig. 1). The initial drop in the antibiotic concentration between $1 \%$ and $5 \%$ hog mucin was not maintained; mucus concentrations above $5 \%$ produced a gradual decrease in antibiotic concentration as the concentration rose in the column of mucus. Tetracycline and fucidin were both exceptions to this; tetracycline showed only a small initial drop in concentration, due to the antibiotic chelating with the metal ions in the mucin, and the penetration of the mucus by fucidin was nearly linear with mucus concentration.

The concentrations of the antibiotics obtained after diffusion through $1 \mathrm{~mm}$. columns of $15 \%(\mathrm{w} / \mathrm{v})$ hog mucin (Table V) were compared with their molecular weights and chemical structures in order to determine some relationship between antibiotic penetration and structure. No direct correlation between chemical structure and the concentrations of the antibiotics obtained after diffusion could be demonstrated. The molecular weights of the antibiotics, however, were correlated to some extent with the concentrations obtained after diffusion: the higher the molecular weight, the more the antibiotic diffused through the mucus column. 
TABLE V

CONCENTRATIONS OF ANTIBIOTICS OBTAINED AFTER DIFFUSION THROUGH 1 MM. COLUMNS OF pH $7 \cdot 415 \%$ HOG MUCIN FOR 24 HOURS AT $37^{\circ} \mathrm{C}$.

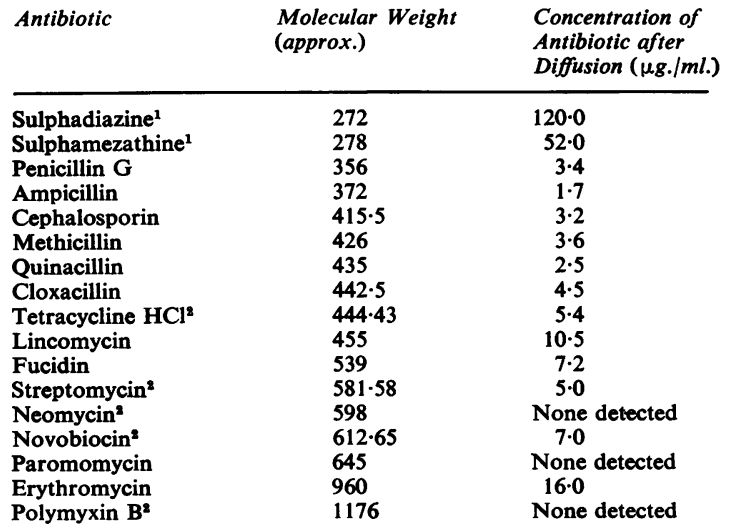

${ }^{1}$ Run at $1,000 \mu \mathrm{g} . / \mathrm{ml}$.

'Bound to mucin

The antibiotic diffusion experiments were also run using $15 \%(\mathrm{w} / \mathrm{v})$ hog mucin pretreated with $5 \%$ (w/v) N-acetyl cysteine. The results (Table VI) show that antibiotic diffusion was considerably reduced in all cases. When the antibiotic was inactivated by $\mathrm{N}$-acetyl cysteine, e.g., penicillin $\mathrm{G}$, no antibiotic was detected after diffusion.

\section{TABLE VI}

CONCENTRATIONS OF ANTIBIOTICS OBTAINED AFTER DIFFUSION FOR 24 HOURS AT $37^{\circ} \mathrm{C}$. THROUGH $1 \mathrm{MM}$. COLUMNS OF PH $7.415 \%$ HOG MUCIN PRETREATED WITH $5 \%(\mathrm{w} / \mathrm{v}) \mathrm{N}$-ACETYL CYSTEINE

$\begin{array}{lll}\text { Antibiotic } & \begin{array}{l}\text { Molecular Weight } \\ \text { (approx.) }\end{array} & \begin{array}{l}\text { Concentration of } \\ \text { Antibiotic after } \\ \text { Diffusion }(\mu \mathrm{g} . / \mathrm{ml} .)\end{array}\end{array}$

\begin{tabular}{|c|c|c|}
\hline 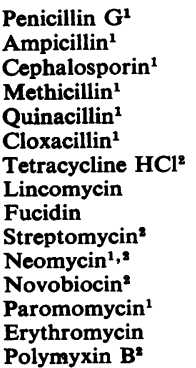 & $\begin{array}{l}356 \\
372 \\
415 \cdot 5 \\
426 \\
435 \\
442 \cdot 5 \\
444 \cdot 43 \\
455 \\
539 \\
581 \cdot 58 \\
598 \\
612 \cdot 65 \\
645 \\
960 \\
1176\end{array}$ & $\begin{array}{l}\text { None detected } \\
\text { None detected } \\
\text { None detected } \\
\text { None detected } \\
\text { None detected } \\
\text { None detected } \\
\text { Trace detected } \\
1 \cdot 2 \\
0 \cdot 9 \\
\text { None detected } \\
\text { None detected } \\
0 \cdot 4 \\
\text { None detected } \\
5 \cdot 0 \\
\text { None deteeted }\end{array}$ \\
\hline
\end{tabular}

${ }^{1}$ Inactivated by $5 \%(\mathrm{w} / \mathrm{v}) \mathrm{N}$-acetyl cysteine

'Bound to mucin

PLASMA TO MUCUS PENETRATION THROUGH HOG MUCIN None of the antibiotics tested diffused through hog mucin at concentrations above $1 \%$ $(\mathrm{w} / \mathrm{v})$ mucin.
DISCUSSION

MUCUS BINDING OF ANTIBIOTICS The binding of antibiotics to mucus is important as it will determine? the proportion of free antibiotic available for diffusion. The bound antibiotic, apart from being $\frac{\overline{\bar{N}}}{\bar{N}}$ bacteriologically inactive, would not readily diffuse $\frac{\text { }}{-}$ into the surrounding environment (Rolinson, 1964)을 which would be an important consideration in the treatment of cystic fibrosis. The tetracyclines were $\vec{\circ}$ partially bound to the mucus by chelation with the metal ions it contained. Chernick and Barbero (1959) $\vec{\omega}$ found that tracheo-bronchial secretions in cystic? fibrosis had a comparatively high calcium content? and this would affect the activity of the tetracycline $\vec{\omega}$ group of antibiotics. The differences between the binding of the test antibiotics to hog and fibrocystic ${ }_{-}^{\omega}$ mucins can be accounted for by the variations in the chemical structures of the test mucins.

DIFFUSION OF ANTIBIOTICS THROUGH 1 MM. COLUMNS OF HOG MUCIN A number of points are discussed here concerning the structure of the antibiotics and their possible relationships to their penetrability.

The penicillin group of antibiotics after diffusion through $15 \%$ hog mucin gave penetration values of 3.2 to $4.5 \mu \mathrm{g}$./ml. with the exceptions of ampicillin and quinacillin, which do not differ radically from the other penicillins in their chemical structures. The $\stackrel{\square}{\mathscr{Q}}$ only major difference shown by these two antibiotics $\vec{F}$ is that they carry different electrical charges at 3 normal $p \mathrm{H}$ than the other test penicillins. The? majority of penicillin molecules are polarized ato normal $p \mathrm{H}$, having one negative charge on the carboxyl group attached to the thiazolidine ring? system. Ampicillin, however, also has a charged $\frac{3}{3}$ amino group on the side chain making the molecule electrically neutral; quinacillin has a negatively ${ }_{3}$ charged carboxyl group on the side chain giving the molecule a double negative charge. The different 5 electrical charges on these molecules may account $>$ for their relatively low penetration values through hog mucin.

The antibiotic lincomycin, which is chemically distinct from all the other test antibiotics, gave the second highest mucus penetration value. No struc- $\omega$ tural reason for this was evident.

Erythromycin, fucidin, and novobiocin all conso tained benzene ring systems linked by common $\Phi$ carbon atoms. These antibiotics all gave good ${ }^{+}$ penetration values. The amounts of these antibiotics - that penetrated the mucus column were all above $\frac{\overrightarrow{ }}{\mathrm{s}}$ $7 \mu \mathrm{g} . / \mathrm{ml}$. Whether the structural similarity is? significant is debatable.

Neomycin, paromomycin, and streptomycin are all derived from various sugars. Streptomycin was 
the only one of this group that penetrated the mucus but there was no apparent reason for this.

Neomycin, novobiocin, polymyxin B, streptomycin, and tetracycline were all bound to hog mucin, which would have reduced their penetration values. Penetration of the $15 \%$ hog mucin could not be detected in the cases of neomycin and polymyxin, but for the other bound antibiotics good penetration values were obtained.

The larger antibiotic molecules diffused more rapidly through $15 \%$ hog mucin than the small antibiotic molecules. It seems possible that some form of gel filtration was taking place in the mucus, the smaller antibiotic molecules becoming trapped in pores in the cross-linked mucopolysaccharides and the larger molecules being unable to pass into the pores in the mucin and so diffusing round the outside of the mucus plug.

The action of $\mathrm{N}$-acetyl cysteine on the penetration of antibiotics through $15 \%$ hog mucin caused a reduction in the penetration values obtained. A possible reason for the lower antibiotic penetration values is that the $\mathrm{N}$-acetyl cysteine breaks down the cross linkages in the mucus causing slower diffusion.

Clinical APPLICATIONS OF THESE FINDINGS The penetration of mucus by aerosolized antibiotics may not be important in the treatment of lung infection itself, as these areas can be effectively reached via the blood stream. It is, however, desirable to sterilize mucus in the respiratory tract and to this end a combination of antibiotic therapy via the blood stream and by aerosol may be used. When choosing an antibiotic for use in an aerosol, next to its antibacterial properties consideration should be given to its mucus penetrability, bearing in mind that high molecular weight antibiotics have the best penetration rates. Antibiotics which are bound to mucus will not be very effective as antibacterial agents and the use of these should be avoided if possible. These conditions when fulfilled should lead to a more effective control of infected sputum.

Acknowledgement is made to the Cystic Fibrosis Research Foundation Trust for the grant under which this work was done.

\section{REFERENCES}

Albert, A. (1952). Nature (Lond.), 172, 201.

(1956). Ibid., 177, 403.

Bond, J. M., Lightbown, J. W., Barber, M., and Waterworth, P. (1963). Brit. med. J., $2,956$.

Bond, J. M. (1964). Postgrad. med. J., 40, suppl. (International Conference on Therapy with the New Penicillins), 17.

Bratton, A. G., and Marshall, E. K. (1939). J. biol. Chem., 128, 537.

Chernick, W. S., and Barbero, G. J. (1959). Pediatrics, 24, 739.

Lawson, D., and Saggers, B. A. (1965). Brit. med. J., 1, 317.

Rolinson, G. N. (1964). Postgrad. med. J., 40, suppl. (International Conference on Therapy with the New Penicillins), 20.

Saggers, B. A. (1966). J. clin. Path., 19, 201. 